\title{
Statistical maps for comparative visualization of landscape changes for industrial centers from different countries
}

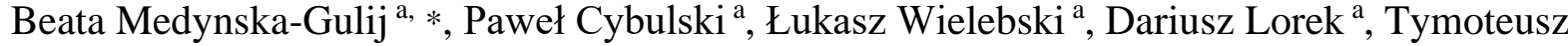 \\ Horbinski $^{\text {a }}$ \\ ${ }^{a}$ Affiliation for all authors: Department of Cartography and Geomatics, Adam Mickiewicz University, Poznan, Poland \\ bmg@amu.edu.pl,p.cybulski@amu.edu.pl,lukwiel@amu.edu.pl,kubal@amu.edu.pl,tymoteusz.horbinski@amu.edu.pl, \\ * Corresponding author
}

Keywords: visualizing landscape and cultural changes, industrial areas, statistical maps, grid cell maps, comparative analysis, topographical maps

\begin{abstract}
:
This study raises the issue of visualizing landscape and cultural changes from the beginning of the nineteenth century to this day. Statistical maps are very helpful in spatial visualizations, however, the process of designing them may be very complex. Contemporary cartographic materials are very easy in terms of processing, unfortunately, the materials from the nineteenth century need more transformation in order to be useful for statistical analysis.
\end{abstract}

The data source included the Prussian non-cartometric Urmesstischblätter topographic map from the beginning of the nineteenth century, Messtischblätter, the Prussian topographic map from the end of the nineteenth century, and current topographic map of two industrial regions in Europe, the Upper Silesia Industrial District in Poland and the Ruhr Area in Germany.

The main aim of this research was to develop and design a set of statistical maps that would depict cultural and landscape changes in two industrial centers, the first one being in Poland and the other one in Germany, from the beginning of the nineteenth century to this day. The authors would also like to demonstrate and describe the geomatic process that led to statistical visualizations.

Various methods were employed in this study to create spatial visualizations: the rectification of the cartographic material, vectorization, and generalization of the selected environment and cultural features, computation of areal and linear differences, and finally, the design of spatial statistical visualization for both regions.

The results were presented in the form of the set of regular square fishnet choropleth maps (grid cell maps) of the Upper Silesia Industrial District in Poland and the Ruhr Area in Germany (two examples on Figure 1 and Figure 2). Thanks to them, the changes in the landscape and cultural space could be visualized and the comparative analysis could be carried out in order to find similarities and differences in the development of geography of those two regions. The research was funded by the German-Polish Science Foundation. 


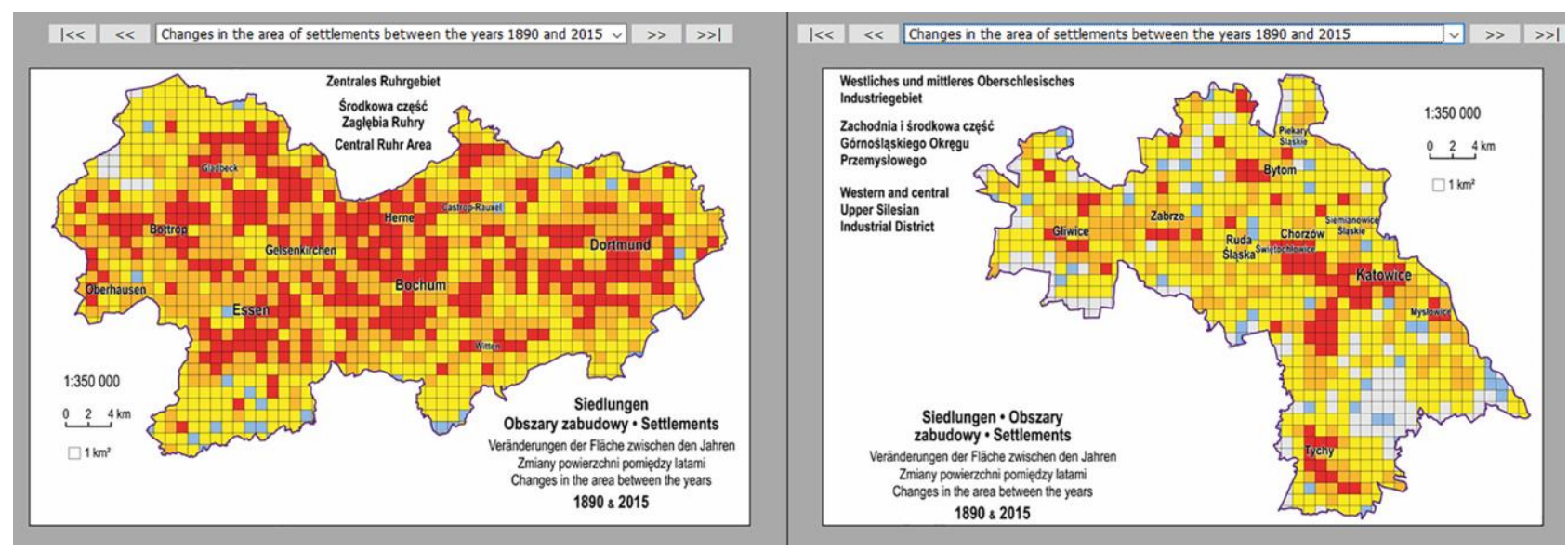

Figure 1. Changes in the area of settlements between the years 1890 and 2015

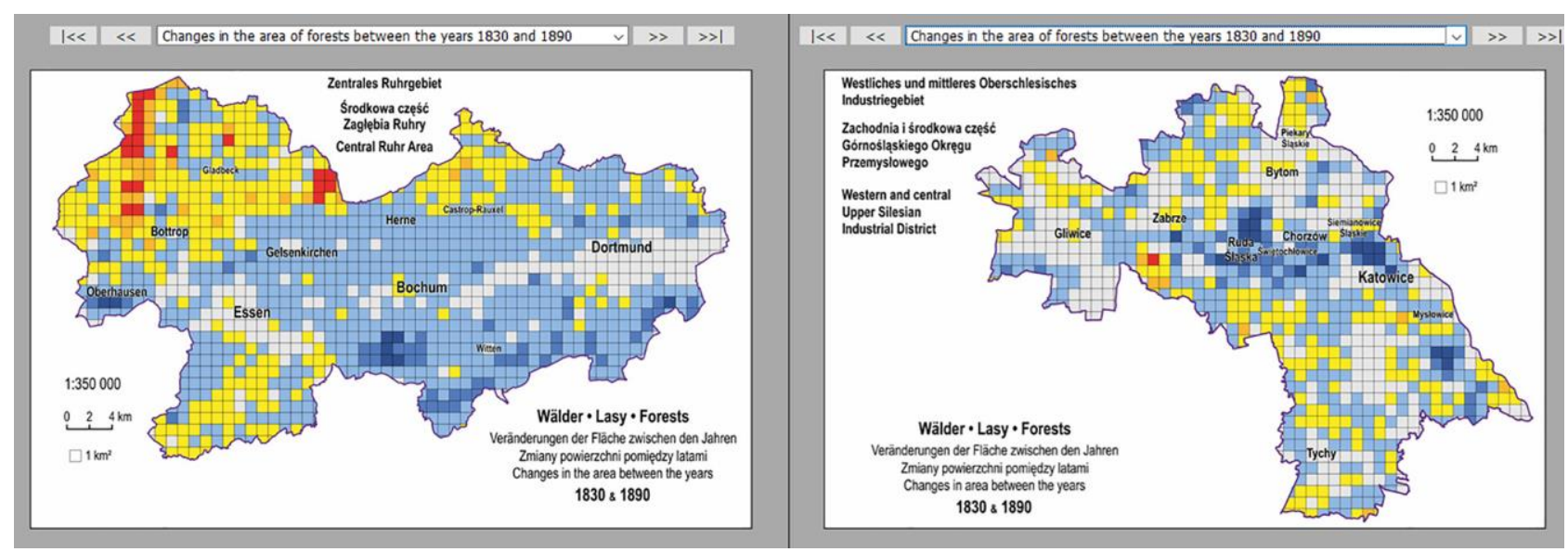

Figure 2. Changes in the area of forests between the years 1830 and 1890 